\title{
Effects of Regional Income, Race, and Educational Level on Incidence of Diabetes and Heart Disease in Ohio
}

\author{
James R. Bolchalk'; Sanhita Gupta ${ }^{1}$ \\ ${ }^{1}$ Kent State University, Geauga Campus, Burton, OH \\ Corresponding Author: James R. Bolchalk, 14111 Claridon-Troy Road, Burton, OH 44021, (330) 559-5370, jbolchal@kent.edu \\ Submitted February 11, 2021 Accepted September 27, 2021 Published January 28, 2022 https://doi.org/10.18061/ojph.v4i2.8121
}

\begin{abstract}
Background: Socioeconomic factors such as income, education, race, age, and weight are thought to be contributing factors for the incidence of chronic diseases such as diabetes and cardiovascular disease. Diabetes and cardiovascular disease are not only serious health complications but also cause significant financial burden to the health care system, both in Ohio and the US. This study seeks to examine the relationship of these socioeconomic factors to the prevalence of these 2 diseases in Ohio using the data available from Behavioral Risk Factor Surveillance Systems (BRFSS).
\end{abstract}

Methods: Fourteen regions in Ohio were analyzed using logistic regression for socioeconomic impacts on diabetes and cardiovascular disease. Data for this study were obtained from the Behavioral Risk Factor Surveillance Systems (BRFSS) for the years 2011 through 2018.

Results: Our results indicate that a strong relationship exists between age and weight with both diabetes and cardiovascular disease in all 14 regions of Ohio, as expected. However, the contribution of the other socioeconomic factors, except income and education levels, is less certain.

Conclusion: This study suggests that besides promoting public health programs that focus on weight and age, effort should be made to evolve strategies promoting increased levels of income augmentation in the population.

Keywords: Diabetes; Cardiovascular disease; Socioeconomic factors; Ohio

\section{INTRODUCTION}

Diabetes is a group of metabolic disorders characterized by increased level of glucose in blood, either due to deficiency of the hormone insulin or the inability to utilize insulin adequately in the body of the affected. ${ }^{1}$ Type 2 diabetes, the most common form of diabetes among adults, happens when either insulin is not made in adequate amounts, is not utilized appropriately even when present, or both the aforementioned conditions exist at the same time. ${ }^{2}$ Uncontrolled diabetes may lead to serious health complications such as kidney disease, cardiovascular disease, increased risk of infection, neuropathy, and blindness. ${ }^{3}$
In addition to the morbidity and mortality associated with diabetes, treatment for diabetes is expensive and increases economic burden on the health care system both in Ohio and in the US. ${ }^{4}$ According to the Ohio Diabetes Action Plan, 2018, Centers for Disease Control and Prevention (CDC) estimated that the expenditure incurred due to diabetes in Ohio is $\$ 15.8$ billion per year. The estimated costs include direct health care costs, loss due to inability to work, and mortality. ${ }^{4}$ Many studies have predicted behavioral risk factors that include but are not limited to sedentary lifestyle, smoking, advanced age, obesity, diet, or urbanization. ${ }^{4-9}$ It would be reasonable to presume that in addition to making changes in lifestyle and behavior, as suggested by previous studies, identify- 
ing socioeconomic factors affecting prevalence of diabetes and making an effort to modify those can also help in decreasing the financial burden. ${ }^{10,11}$

Another group of diseases known as cardiovascular disease (CVD) is the leading cause of mortality in the Western world and the risk factors are similar to those in diabetes, which include smoking, lack of physical activity, poor nutrition, and obesity. ${ }^{12,13}$ At one time CVD was thought to be the disease of affluence, prevalent in the Western world. ${ }^{14}$ Evidence collected since then has indicated that socioeconomically disadvantaged population, that is, individuals belonging to moderate- or low-income groups are also at risk. ${ }^{14}$ Among the factors deemed responsible for morbidity and mortality due to CVD, diet and diet-related conditions and behavior are of utmost importance. ${ }^{15,16}$ Part of the cause of CVD in those belonging to the lower income groups may therefore be attributed to quality of nutrition which is dictated in part by economic affluence or lack thereof.

As mentioned, quality of nutrition affects both type 2 diabetes and CVD, the 2 diseases that are the focus of this study. ${ }^{8,15,16}$ Severe discrepancies exist between the diets of those belonging to the different socioeconomic levels. The difference in diets is not only due to affordability but also due to availability of quality food items, awareness, cultural influence, and area of residence. Studies have suggested that people of low socioeconomic status tend to spend most of their resources on food items of low nutritional value such as packaged food, food with high sugar and saturated fat content, and less on more nutritious fresh produce, lean meats, and fish. ${ }^{17-19}$ This is compounded by limited access to supermarkets where healthy food items are available and by lack of will or means to exercise. ${ }^{19}$ Another factor that contributes to cardiovascular health is alcohol consumption. It has been shown that although moderate consumption of alcohol may be beneficial to cardiovascular health,20,21 regular consumption of large quantities may have adverse effects. ${ }^{22-24}$ Members of the population belonging to the socioeconomically disadvantaged group drink large quantities of beer and sweetened beverages as opposed to the socially advantaged who consume wine known to be beneficial to health. ${ }^{25}$ Another factor that contributes to all causes of mortality is education. Galea et $\mathrm{al}^{26}$ reported that in the year 2000 , education could have significantly reduced all causes of mortality, a vast majority of which could be accounted for by cardiovascular diseases. It is well known and accepted that socioeconomic disparities can be correlated with inequalities in cardiovascular health. ${ }^{27-29}$

The role of socioeconomic factors causing increased risk for diabetes and CVD has been studied in other regions of the US and the world, however, relatively fewer studies have been conducted in Ohio. Schwartz et al examined the self-reported cases of diabetes in the 11 Appalachian counties of Ohio and found a disproportionate number of cases in this region compared to the state and na- tional averages. ${ }^{30}$ Individual counties sometimes issue reports concerning diseases such as diabetes, and the Ohio Department of Health issues an annual report based on the BRFSS survey, but comprehensive analyses of the socioeconomic aspects of the disease are lacking. ${ }^{31,32}$ This study attempts to partially fill the gap in regional aspects of the incidence of diabetes and heart disease.

\section{METHODS}

\section{Participants}

Survey data originating from individual counties in Ohio are rare, therefore, data from the Ohio Behavioral Risk Factor Surveillance System (BRFSS) for the years 2011 through 2018 were used for this study. The BRFSS survey collects, "prevalence data among adult U.S. residents regarding their risk behaviors," including those behaviors that can affect their health status including the causes of preventable deaths in the adult population in each state. ${ }^{33}$ The Ohio BRFSS survey was conducted by a private contractor that used both landlines and cell phones to randomly (random-digit-dialing) interview 700 to 1000 noninstitutionalized adults (18 years or older) per month. ${ }^{34}$ The state-collected crosssectional data are then sent to the CDC where they are aggregated, edited, and weighted. ${ }^{33}$ Data are weighted using iterative proportional fitting to account for the increased use of cell phones and to include other characteristics such as education level, marital status, and home ownership. ${ }^{35}$

\section{Setting and Design}

The Ohio Department of Health (ODH) has created 14 regions within the state based on existing geographic and underlying demographic data (J. Sleesman, ODH, personal communication, June $29,2021)$. These regions are listed in Table 1 . These regional groupings were used in our model to coincide with the state information and for comparison purposes. Besides regions, other socioeconomic variables of interest were age, weight, years of education, level of income, and race. Age and weight are known to be positively related to the higher incidences of both diabetes and heart disease. ${ }^{2}$ The other factors of income, education, and race are socioeconomic and are also thought to be factors in the incidence of both diseases. ${ }^{36}$ Some studies show disparities between urban and rural areas regarding disease, but regions, on a statewide basis, have not been examined to any great extent.

The CDC changed the weighting methodology for BRFSS data in 2011, therefore Ohio BRFSS data for the years 2011 through 2018 were used to examine the relationships between reported diabetes and reported heart disease in each county in Ohio.

\section{Procedures and Measures}

Access to use the Ohio BRFSS survey data in this study was approved by the Ohio Department of Health and sent electronically to the authors in SAS format. ${ }^{a}$

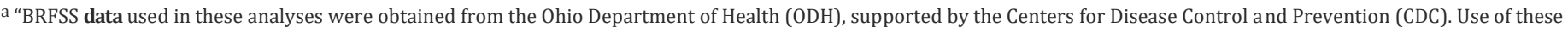

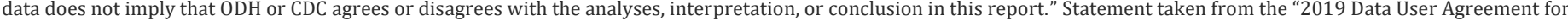
Access to Ohio Behavioral Risk Factor Surveillance System (BRFSS)." 


\section{Table 1. County Regional Groupings}

\begin{tabular}{|ll|}
\hline Region 1 & Defiance, Fulton, Henry, Lucas, Paulding, Williams, Wood \\
Region 2 & Allen, Auglaize, Hancock, Hardin, Mercer, Putnam, Van Wert \\
Region 3 & Crawford, Erie, Huron, Ottawa, Richland, Sandusky, Seneca, Wyandot \\
Region 4 & Cuyahoga, Geauga, Lake, Lorain \\
Region 5 & Ashland, Holmes, Medina, Stark, Summit, Wayne \\
Region 6 & Ashtabula, Columbiana, Mahoning, Portage, Trumbull \\
Region 7 & Delaware, Knox, Marion, Morrow, Union \\
Region 8 & Fairfield, Franklin, Licking, Madison, Pickaway \\
Region 9 & Champaign, Clark, Darke, Greene, Logan, Miami, Montgomery, Preble, Shelby \\
Region 10 & Butler, Clermont, Clinton, Hamilton, Warren \\
Region 11 & Adams, Brown, Fayette, Highland, Pike, Ross, Scioto \\
Region 12 & Coshocton, Guernsey, Morgan, Muskingum, Noble, Perry, Tuscarawas \\
Region 13 & Belmont, Carroll, Harrison, Jefferson, Monroe, Washington \\
Region 14 & Athens, Gallia, Hocking, Jackson, Lawrence, Meigs, Vinton \\
\hline
\end{tabular}

Outcome Variable-Diabetes

In the BRFSS surveys, the incidence of type 2 diabetes was established by asking each participant, "(Ever told) you have diabetes? Response: 1 =Yes; 2 = Yes, but female told only during pregnancy; 3 = No; 4 = No, prediabetes or borderline diabetes; 7 = Don't know $/$ Not sure; $9=$ Refused." 37

\section{Outcome Variable-Heart Disease}

Similarly, to determine incidence of heart disease, the survey question was, "(Ever told) you had angina or coronary heart disease? Response: $1=$ Yes, $2=$ No, 7 =Don't know $/$ Not sure, 9 = Refused." 37 The predictor variables of age, weight, level of education, and level of income were also determined from the BRFSS surveys for each year.

\section{Predictors-Age and Weight}

These 2 continuous variables were answered in the BRFSS survey simply by asking the questions, "What is your age?" and, "About how much do you weigh without shoes?"37 The expected answer for weight was to be in pounds. If the answers were given in metric form, the data were recoded to obtain answers in pounds. Age was recoded to count only those individuals 18 years and older while weight was recoded to calculate weight in pounds.

Predictor-Income

The BRFSS survey asked respondents, "Is your annual household income from all sources: 1) Less than $\$ 10000,2)$ Less than $\$ 15000,3)$ Less than $\$ 20000,4)$ Less than $\$ 25000,5)$ Less than $\$ 35,000,6)$ Less than $\$ 50000,7)$ Less than $\$ 75000,8) \$ 75000$ or more?" 37 The individuals were classified into 1 of the 8 levels. Those responses were recoded into 5 levels for our model for ease of calculation.

1. Less than $\$ 25000$

2. Greater than or equal to $\$ 25000$ and less than $\$ 35000$
3. Greater than or equal to $\$ 35000$ and less than $\$ 50000$

4. Greater than or equal to $\$ 50000$ and less than $\$ 75000$

5 . Greater than or equal to $\$ 75000$

Predictor-Level of Education

The initial survey question was, "What is the highest grade or year of school you completed?" 1) Never attended school or only kindergarten, 2) Grades 1 through 8, 3) Grades 9 through 11, 4) Grade 12 or GED, 5) College 1 to 3 years, 6) College 4 years or more."37 For this study, the 6 levels were pared down to the following 4 levels.

1. Less than high school

2. Grade 12 or GED

3. College 1 to 3 years

4. College 4 years or more

Predictor-Race

Respondents were asked to identify their race or ethnicity. Five categories of race were included in the study as a calculated value to adhere to standardized reporting for race and ethnicity. The categories of race are: 1) White only, non-Hispanic, 2) Black only, non-Hispanic, 3) Other race only, non-Hispanic, 4) Multiracial, non-Hispanic, 5) Hispanic. ${ }^{37}$

\section{Predictor-Region}

Since the study was concerned with regional effects, the 14 regions (Region 1 through 14) were also included as predictors. The BRFSS survey included county of residence information. The SAS model was coded to group residents into 1 of the 14 regions based on their county of residence.

\section{Statistical Analysis}

A logistic regression model was used to analyze the relationship because of the dichotomous outcome variables and both continu- 
ous and categorical predictor variables. The SAS PROC SURVEYLOGISTIC procedure was used to provide the statistical analysis. ${ }^{\mathrm{b}}$ The SAS program was especially compatible with the datasets provided because of its ability to account for survey weighting.

Logistic methods of analysis first estimate coefficients for the independent variables, which are then used to determine odds ratios. The odds ratios are determined by comparing the categorical interval under consideration to a reference interval. The references were selected based on the worst possible outcome within their respective categorical range except for race. For example, for the income variable, the income reference was "Income $<\$ 25000$." Income less than $\$ 25000$ was selected as the reference group because household income for a family of 4 below $\$ 25000$ suggests the household is living in poverty. For educational level, "Less than high school" was selected as the reference group because those individuals who fall within this category have decreased chances for good paying jobs and the associated benefits. Of the 14 regions included in the study, "Region 14" was selected as the reference because it was the poorest region in the state in terms of income. For the 8 years of the study, Region 14 ranked last in average median incomec in 7 of those 8 years. ${ }^{38}$ In addition, the Appalachian Regional Commission considers Athens and Meigs counties in Region 14 as "distressed." The distressed rating is based not solely on income but other factors such as poverty and unemployment as well. ${ }^{39}$ In determining the reference for race, non-Hispanic Whites was used as the reference group because this group has relatively lower rates of heart disease and diabetes. ${ }^{40,41}$

Logistic regression models should meet the assumptions associated with their use. Basically, 5 assumptions were examined regarding the model and data: 1) the dependent variable must be binary, 2) observations should be independent of each other, 3) the absence of multicollinearity, 4) linearity between continuous independent variables and the log odds of the dependent variable, and 5) the use of a large sample size. ${ }^{42-44}$ The use of the dichotomous variable, having diabetes or heart disease, as dependent variables satisfy the first assumption. The second assumption was satisfied because the survey was conducted with independent random phone calls. To check for multicollinearity, a correlation matrix was obtained from the model and examined for highly correlated relationships. No significant correlations among independent variables were observed. Also, as part of the model, scatterplots were examined for each model comparing the log odds of the dependent variable to the continuous variables of age and weight. Visual examination of these plots showed an excellent linear pattern for log odds of both diabetes and heart disease versus age, while the plot for weight was not as clear. This could be because both diabetes and heart disease are related to an individual being obese and obesity is related to one's body mass index (BMI). Since BMI is a function of both weight and height, some people could be obese at 180 pounds, while others would not. This could account for the unusual plots for weight (K. Yeager, Kent State UniversityStatistical Consultant, personal communication, February 8, 2021). For assumption 5, a minimum sample size of a least 500 is recommended for logistic regression. ${ }^{44}$ Sample sizes for all 16 models in our study approached 10000 observations, which is quite sufficient to meet the assumption.

In addition to meeting the assumptions, the models underwent global null hypothesis tests to discern whether they fit the data better than an empty model. The likelihood ratio test, the efficient score test, and the Wald test were used to make this determination. Essentially, these tests are examining whether the model has at least 1 predictor that is relevant in explaining whether an individual has diabetes or heart disease. ${ }^{45}$ For this study, all 16 models met all 3 global tests.

\section{RESULTS}

Table 2 displays the results of the analysis of effects or whether each of the predicator variables as a group affects the outcome variables. The age and weight predictors were significant for the entire time of the study for both diabetes and heart disease. Income was significant for all 8 years for diabetes and for 6 of the 8 years for heart disease. Race was a significant effect for 5 years for diabetes, but only 3 years for heart disease. Education and region were considerably less influential for both diseases.

To examine the effects in more detail the results of the maximum likelihood estimated logistic regression coefficients are displayed in Tables 3 and 4 along with their respective significance. The coefficients represent the change in log odds of the outcome for a 1 unit increase in the predictor variable. For example, in determining the incidence of diabetes, the coefficient on the predicator variable, "Income $\geq \$ 75000$ " in 2018 was -0.3859 . For a 1 unit change in the income predictor, the log odds of getting diabetes decrease by -0.3859 compared to those with an income below $\$ 25000.46$

As expected, age and weight were significant positive factors contributing to the incidence of both diabetes and heart disease for all 8 years of the study. In 7 of the 8 years, households with income levels below $\$ 35000$ had a positive relationship to the incidence of diabetes as indicated by the positive coefficient as compared to those with incomes less than $\$ 25000$. Households having income levels greater than $\$ 50000$ and less than $\$ 75000$ had negative relationships to incidence of diabetes in 6 of the 8 years compared to those with incomes less than $\$ 25000$. Households with income levels greater than $\$ 75000$ had statistically significant negative relationship to the incidence of diabetes all 8 years compared to

\footnotetext{
b The analysis for this paper was generated using SAS 9.4 software. Copyright (C) 2002-2012 SAS Institute Inc. SAS and all other SAS Institute Inc. product or service names are registered trademarks or trademarks of SAS Institute Inc., Cary, NC, USA.

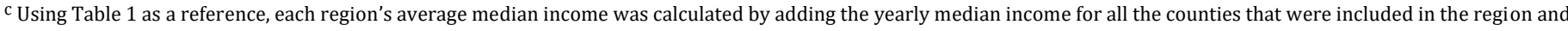
then dividing by the number of counties. Data were obtained from the US Census yearly median income per county tables. Calcul ations available upon request from authors.
} 


\begin{tabular}{|c|c|c|c|c|c|c|c|c|}
\hline \multicolumn{9}{|l|}{ Diabetes } \\
\hline & 2011 & 2012 & 2013 & 2014 & 2015 & 2016 & 2017 & 2018 \\
\hline \multicolumn{9}{|l|}{ Effect } \\
\hline Weight & $204.52^{\star *}$ & $256.83^{* *}$ & $220.27^{\star \star}$ & $238.32^{* *}$ & $183.29 * *$ & $96.71^{\star *}$ & $197.43^{* \star}$ & $209.59 * *$ \\
\hline Education & 1.26 & 2.29 & 2.41 & 1.56 & $2.66^{*}$ & 0.67 & 0.74 & 1.91 \\
\hline Income & $2.88^{*}$ & $7.71^{\star *}$ & $3.29 *$ & $11.03^{* *}$ & $2.82^{*}$ & $4.33^{\star *}$ & $11.86^{* *}$ & $9.50^{\star *}$ \\
\hline Age & $233.22^{\star \star}$ & $319.56^{\star \star}$ & $361.97^{\star \star}$ & $318.21^{\star \star}$ & $334.37^{* \star}$ & $317.25^{\star \star}$ & $305.85^{\star \star}$ & 304.19 ** \\
\hline Race & $5.00^{\star *}$ & $3.01^{*}$ & $3.61^{* *}$ & $3.56^{\star \star}$ & $2.54^{*}$ & 1.51 & 2.07 & 0.68 \\
\hline Region & 1.24 & 1.06 & $1.84^{*}$ & 1.21 & 1.14 & 1.49 & $2.32^{\star \star}$ & 1.48 \\
\hline \multicolumn{9}{|c|}{ Heart Disease } \\
\hline & 2011 & 2012 & 2013 & 2014 & 2015 & 2016 & 2017 & 2018 \\
\hline \multicolumn{9}{|l|}{ Effect } \\
\hline Weight & $67.98^{\star *}$ & $55.75^{\star \star}$ & $35.14^{\star \star}$ & $42.05^{\star \star}$ & $24.32^{\star \star}$ & $51.99 * *$ & $26.70^{\star \star}$ & $49.56^{\star \star}$ \\
\hline Education & 1.98 & $3.13^{*}$ & 1.11 & 0.50 & 0.87 & $6.42^{\star *}$ & 0.01 & 1.97 \\
\hline Income & $4.45^{\star \star}$ & $3.89 * \star$ & $4.48^{\star \star}$ & $4.82^{\star \star}$ & $4.43^{\star \star}$ & 2.23 & $5.45^{\star \star}$ & 1.40 \\
\hline Age & $261.90^{\star *}$ & $213.31^{\text {** }}$ & $366.24^{\star *}$ & $276.29 * \star$ & $216.15^{\star *}$ & $179.57^{\text {** }}$ & $377.28^{\star \star}$ & $274.68^{* *}$ \\
\hline Race & $3.03^{\star \star}$ & 1.63 & $5.62^{\star *}$ & 1.48 & 1.21 & 1.60 & 2.07 & $3.01^{\star}$ \\
\hline Region & 0.64 & 1.41 & 0.58 & 1.31 & $2.77^{\star \star}$ & 0.99 & $2.21^{\star \star}$ & 0.63 \\
\hline
\end{tabular}

*Denotes $p<0.05$

${ }^{*}$ Denotes $p<0.01$

those with incomes less than $\$ 25000$. The Analysis of Effects table indicated that for the 5 years from 2011 through 2015, race was a significant factor, however, the analysis of the coefficients only showed significance for non-Hispanic Blacks for 2011 and 2012 and for other races (besides non-Hispanic Black, Hispanics, and Multiracials) for 2012 and 2013 compared to non-Hispanic Whites.

For the incidence of heart disease, Table 4, income level had similar effects, albeit not as strong. At income levels above $\$ 75000$, negative relationships existed compared to those with incomes less than $\$ 25000$ but were only statistically significant 4 years out of the 8. Once again incomes below $\$ 35000$ seem to establish a positive association for heart disease, while income levels greater than $\$ 35000$ and less than $\$ 50000$ indicated negative relationships in 5 of the 8 years compared to those with incomes less than $\$ 25000$. Income levels greater than $\$ 50000$ and less than $\$ 75000$ had negative coefficients 6 of 8 years and at the greater than $\$ 75000$ level all 8 years were negative compared to those with incomes less than $\$ 25000$.

The coefficient values of the logistic regression are used to calculate an odds ratio, which is the multiplicative change in the odds for a 1 unit change in a predicator variable. For example, in Table 5 , the odds ratio point estimates for diabetes for those with "Income $>\$ 75000$ vs $<\$ 25000$ " in 2018 is 0.446 . Since 0.446 is less than 1 , the interpretation is the odds a person whose income was greater than or equal to $\$ 75000$ would be less likely to have diabetes than a person whose income was less than the $\$ 25000.47$ In this case, the odds of a person with an income greater than $\$ 75000$ acquiring diabetes would decrease by 55.4\% $(1-0.446=$ 0.554 ) compared to a person with an income of less than $\$ 25000$. If the odds ratio point estimate was greater than 1 , then the person whose income was greater than $\$ 75000$ would have higher odds of developing diabetes compared to the person whose income was less than $\$ 25000$. The results for all odds ratios are found in Tables 5 and 6.

\section{DISCUSSION}

Perhaps the most interesting finding for incidence of diabetes was at a certain level of income, the sign on the logistic regression coefficient changes from positive to negative. For each year of this study, income levels within the range of $\$ 35000$ to $\$ 50000$ and $\$ 50000$ to $\$ 75000$ have negative coefficients in 6 of the 8 years. When the range of income is greater than $\$ 75000$, all 8 years show a negative coefficient. The implications of the negative coefficients are that not only are individuals at an advantage with higher incomes in terms of the incidence of diabetes, but also the turning point in terms of better diabetes outcomes seems to be when income increases to at least $\$ 35000$. One Canadian study 48 has indicated that income below $\$ 29000$ is significantly related to a higher incidence of diabetes and another study indicated that the gap is widening. ${ }^{49}$

The income effect on incidence of heart disease was similar but not quite as strong. At the $\$ 35000$ to $\$ 50000$ level, negative coef- 
Table 3. Logistic Regression Estimates for Incidence of Diabetes per year

\begin{tabular}{|c|c|c|c|c|c|c|c|c|}
\hline Parameter & 2011 & 2012 & 2013 & 2014 & 2015 & 2016 & 2017 & 2018 \\
\hline Intercept & $-8.0769 * \star$ & $-7.5892^{\star \star}$ & $-8.0353^{\star \star}$ & $-7.9558^{\star \star}$ & $-8.2259 * *$ & $-7.0276^{\star \star}$ & $-7.3268^{\star \star}$ & $-7.6728^{\star *}$ \\
\hline Weight & $0.0159 * \star$ & $0.0143^{\star *}$ & $0.0148^{\star \star}$ & $0.0149 * \star$ & $0.0138^{* \star}$ & $0.0116^{\star \star}$ & $0.0127^{\star \star}$ & $0.0135^{\star \star}$ \\
\hline College 1 - 3 years & -0.0567 & 0.1114 & 0.0952 & 0.1624 & $0.2005^{\star}$ & -0.0270 & 0.0597 & 0.1394 \\
\hline College $>4$ years & -0.1588 & $0.1771^{\star}$ & $-0.2509^{\star}$ & -0.0723 & -0.1501 & -0.1156 & -0.0684 & -0.0776 \\
\hline Grade 12 or GED & 0.0952 & -0.0592 & 0.0629 & 0.0746 & 0.1244 & -0.0184 & 0.0901 & -0.0902 \\
\hline Income $\geq \$ 25 k<\$ 35 k$ & 0.2064 & 0.0858 & 0.1588 & 0.1566 & $0.2270^{*}$ & -0.1256 & $0.3053^{*}$ & 0.1026 \\
\hline Income $\geq \$ 35 k<\$ 50 k$ & -0.0493 & 0.1509 & -0.0804 & $-0.2528^{*}$ & -0.0828 & 0.0632 & -0.1590 & 0.1108 \\
\hline Income $\geq \$ 50 k<\$ 75 k$ & 0.0108 & $-0.2434^{*}$ & -0.0500 & -0.0512 & -0.1319 & 0.0075 & -0.1288 & $-0.2493^{\star *}$ \\
\hline Income $\geq \$ 75 \mathrm{k}$ & $-0.3348^{* *}$ & $-0.3140^{\star *}$ & $-0.3010^{\star}$ & $-0.3773^{\star \star}$ & $-0.2263^{*}$ & $-0.2424^{\star}$ & $-0.4182^{\star \star}$ & $-0.3859 * *$ \\
\hline Age & $0.0552^{\star \star}$ & $0.0513^{\star *}$ & $0.0608^{\star *}$ & $0.0581^{\star *}$ & $0.0616^{\star \star}$ & $0.0560 * \star$ & $0.0551^{* *}$ & $0.0529 * *$ \\
\hline Hispanic & -0.2351 & 0.2200 & -0.1583 & 0.1229 & 0.6049 & 0.1883 & 0.3268 & 0.2952 \\
\hline Multi-Racial & -0.5258 & 0.1056 & 0.0099 & -0.2159 & -0.6614 & 0.2913 & -0.3193 & -0.0688 \\
\hline Non-Hispanic Black & $0.4948^{\star}$ & $0.3897^{\star}$ & -0.1033 & 0.2118 & 0.2931 & -0.1749 & -0.0559 & 0.1351 \\
\hline Other Race & 0.5212 & $-0.6708^{*}$ & $0.6838^{*}$ & 0.2204 & -0.1561 & 0.0479 & 0.3679 & -0.4439 \\
\hline Region 1 & 0.0668 & 0.0782 & -0.0106 & 0.0497 & 0.0642 & -0.0256 & -0.0335 & -0.0122 \\
\hline Region 2 & -0.0955 & $-0.4388^{*}$ & -0.3229 & -0.1181 & $-0.4181^{\star *}$ & -0.0134 & -0.2575 & -0.0763 \\
\hline Region 3 & -0.0593 & 0.0812 & 0.0572 & $-0.3248^{\star}$ & -0.0918 & 0.1522 & -0.1848 & -0.1061 \\
\hline Region 4 & -0.2914 & -0.0359 & 0.1376 & -0.0588 & -0.0911 & $-0.3483^{*}$ & -0.1621 & -0.0251 \\
\hline Region 5 & -0.1155 & 0.0192 & -0.2514 & -0.1133 & -0.1564 & -0.0589 & -0.2359 & -0.1289 \\
\hline Region 6 & -0.2206 & -0.1605 & -0.1333 & -0.2350 & -0.1352 & 0.0452 & -0.0396 & 0.0242 \\
\hline Region 7 & 0.0846 & -0.0291 & -0.1059 & -0.0774 & 0.0053 & -0.2396 & -0.0219 & -0.2232 \\
\hline Region 8 & 0.1023 & -0.1090 & 0.1717 & 0.0720 & -0.0331 & -0.0734 & -0.1385 & 0.1721 \\
\hline Region 9 & -0.0576 & 0.0471 & -0.1297 & 0.1307 & 0.1201 & -0.0297 & 0.0474 & -0.0824 \\
\hline Region 10 & 0.1417 & 0.1333 & -0.0801 & -0.1320 & 0.1959 & 0.1603 & -0.1919 & 0.2465 \\
\hline Region 11 & 0.1370 & $0.4795^{\star}$ & -0.0284 & 0.1566 & 0.2132 & -0.0940 & 0.2638 & 0.2366 \\
\hline Region 12 & -0.1742 & 0.0236 & -0.1731 & 0.2156 & 0.1535 & -0.1116 & $0.2721^{*}$ & $-0.3278^{*}$ \\
\hline Region 13 & $0.6063^{* *}$ & -0.0306 & $0.4493^{* *}$ & 0.1679 & 0.0183 & 0.1488 & 0.2482 & 0.1339 \\
\hline
\end{tabular}

${ }^{*}$ Denotes $p<0.05$

**Denotes $p<0.01$

Table 4. Logistic Regression Estimates for Incidence of Heart Disease per year

\begin{tabular}{|c|c|c|c|c|c|c|c|c|}
\hline Parameter & 2011 & 2012 & $\begin{array}{l}2013 \\
\text { Est. }\end{array}$ & 2014 & 2015 & 2016 & 2017 & 2018 \\
\hline Intercept & $-9.3572^{\star *}$ & $-7.8188^{* *}$ & $-8.6138^{\star \star}$ & $-8.7519 * \star$ & $-8.3388^{\star \star}$ & $-8.3009 * *$ & $-8.0869^{* *}$ & $-8.2390^{* *}$ \\
\hline Weight & $0.0115^{\star \star}$ & 0.0079 & $0.0075^{\star *}$ & $0.0068^{* *}$ & $0.0071^{\star \star}$ & $0.0076^{* *}$ & $0.0071^{\star \star}$ & $0.0071^{* *}$ \\
\hline College 1 - 3 years & -0.0178 & $0.1159^{\star *}$ & -0.1308 & 0.1345 & 0.1852 & -0.1343 & 0.0100 & 0.0552 \\
\hline College $>4$ years & $-0.2661^{\star}$ & -0.3394 & -0.1605 & -0.0232 & -0.0165 & $-0.3602^{\star \star}$ & -0.0215 & $-0.2848^{*}$ \\
\hline Grade 12 or GED & -0.0467 & 0.0424 & 0.1022 & -0.0544 & 0.0307 & -0.1827 & 0.0109 & -0.0046 \\
\hline Income $\geq \$ 25 k<\$ 35 k$ & $0.4251^{\star \star}$ & -0.0422 & 0.1846 & -0.0922 & 0.2558 & -0.1009 & 0.0551 & 0.0039 \\
\hline Income $\geq \$ 35 k<\$ 50 k$ & 0.0133 & -0.2520 & -0.1286 & 0.1920 & -0.1379 & 0.0290 & -0.1853 & -0.0346 \\
\hline Income $\geq \$ 50 k<\$ 75 k$ & -0.2415 & 0.1887 & -0.2294 & -0.1615 & -0.2025 & -0.1448 & -0.1065 & 0.0526 \\
\hline Income $\geq \$ 75 k$ & $-0.4688^{\star *}$ & $-0.2113^{\star *}$ & -0.2664 & $-0.3425^{\star *}$ & $-0.3457^{\star}$ & -0.1204 & -0.2186 & -0.2199 \\
\hline Age & $0.0639^{\star *}$ & 0.0615 & $0.0732^{* *}$ & $0.0728^{* *}$ & $0.0674^{\star \star}$ & $0.0641^{* *}$ & $0.0709^{* *}$ & $0.0730 * *$ \\
\hline Hispanic & $-1.2435^{\star}$ & $0.1574^{*}$ & -0.6280 & -0.6512 & -0.6057 & -0.5606 & 0.4363 & 0.1432 \\
\hline Multi-Racial & 0.4508 & 0.6291 & $1.4432^{\star *}$ & -0.0560 & $0.7752^{*}$ & -0.3353 & 0.0499 & -0.4467 \\
\hline Non-Hispanic Black & 0.2863 & -0.2172 & $-0.8444^{\star *}$ & 0.3185 & 0.0530 & -0.0095 & $-0.6670^{\star *}$ & $-0.5844^{*}$ \\
\hline Other Race & -0.2128 & -0.5476 & 0.0640 & -0.0033 & -0.1943 & 0.5119 & 0.5685 & $1.1396^{\star *}$ \\
\hline Region 1 & -0.1438 & 0.0783 & 0.1119 & 0.1680 & 0.1634 & 0.1844 & 0.2514 & -0.0863 \\
\hline Region 2 & -0.0560 & 0.0392 & -0.2650 & 0.3167 & 0.0723 & 0.3711 & 0.0163 & 0.0241 \\
\hline Region 3 & -0.1344 & 0.0967 & -0.0706 & -0.0813 & -0.2186 & 0.1189 & -0.0061 & -0.1075 \\
\hline Region 4 & 0.0083 & $-0.4175^{\star}$ & 0.0260 & $-0.4097^{\star}$ & -0.4303 & 0.0743 & -0.3140 & -0.0276 \\
\hline Region 5 & 0.0564 & 0.1275 & -0.0541 & -0.2122 & $-0.4567^{\star}$ & 0.0116 & -0.2154 & 0.0530 \\
\hline Region 6 & 0.4027 & -0.0060 & -0.3186 & -0.3354 & -0.0761 & 0.2096 & -0.2531 & 0.0199 \\
\hline Region 7 & -0.1488 & -0.4444 & -0.0749 & -0.0920 & -0.4162 & -0.1632 & -0.2277 & 0.1940 \\
\hline Region 8 & 0.1338 & 0.1671 & 0.1595 & -0.2963 & $-0.4273^{\star}$ & $-0.5307^{\star}$ & $-0.5845^{\star \star}$ & $-0.3791^{*}$ \\
\hline Region 9 & -0.2162 & -0.1675 & -0.0192 & 0.0044 & 0.3945 & -0.0946 & 0.1043 & -0.0215 \\
\hline Region 10 & -0.1860 & -0.0782 & 0.0047 & 0.0210 & -0.0294 & -0.1670 & 0.0749 & -0.0444 \\
\hline Region 11 & 0.0190 & 0.0888 & 0.0610 & 0.2320 & 0.1516 & 0.0963 & 0.3370 & -0.0062 \\
\hline Region 12 & 0.2352 & $0.5193^{\star *}$ & -0.0399 & 0.1829 & 0.4261 & -0.0079 & 0.1493 & -0.1257 \\
\hline Region 13 & 0.2338 & -0.1173 & 0.3365 & 0.3426 & 0.1653 & 0.1341 & 0.1939 & 0.2951 \\
\hline
\end{tabular}

**Denotes $p<0.01$ 
Table 5. Odds Ratio Estimates and Significance for Incidence of Diabetes per year

\begin{tabular}{|c|c|c|c|c|c|c|c|c|}
\hline Parameter & 2011 & 2012 & 2013 & 2014 & 2015 & 2016 & 2017 & 2018 \\
\hline Weight & $1.016^{\star}$ & $1.014^{*}$ & $1.015^{\star}$ & $1.015^{\star}$ & $1.014^{\star}$ & $1.012^{\star}$ & $1.013^{*}$ & $1.014^{*}$ \\
\hline College 1 - 3 years vs < high school & 0.838 & 0.987 & 1.002 & 1.387 & 1.455 & 0.829 & 1.151 & 1.117 \\
\hline College $>4$ years vs $<$ high school & 0.756 & 0.739 & 0.709 & 1.097 & 1.025 & 0.758 & 1.013 & 0.899 \\
\hline Grade 12 or GED vs < high school & 0.975 & 0.832 & 0.970 & 1.270 & 1.349 & 0.836 & 1.187 & 0.888 \\
\hline Income $\geq \$ 25 k<\$ 35 k$ vs $<\$ 25 k$ & 1.040 & 0.791 & 0.893 & $0.692^{*}$ & 1.013 & $0.655^{*}$ & 0.909 & $0.727^{*}$ \\
\hline Income $\geq \$ 35 k<\$ 50 k$ vs $<\$ 25 k$ & 0.806 & 0.844 & $0.703^{*}$ & $0.460^{*}$ & $0.743^{*}$ & 0.791 & $0.571^{*}$ & $0.733^{*}$ \\
\hline Income $\geq \$ 50 \mathrm{k}<\$ 75 \mathrm{k}$ vs $<\$ 25 \mathrm{k}$ & 0.856 & $0.569 *$ & $0.724^{*}$ & $0.562^{*}$ & $0.708^{\star}$ & 0.748 & $0.589^{*}$ & $0.511^{*}$ \\
\hline Income $\geq \$ 75 k$ vs $<\$ 25 k$ & $0.606^{*}$ & $0.530^{*}$ & $0.564^{*}$ & $0.406^{*}$ & $0.644^{*}$ & $0.583^{*}$ & $0.441^{*}$ & $0.446^{*}$ \\
\hline Age & $1.057^{*}$ & $1.053^{*}$ & $1.063^{*}$ & $1.060^{*}$ & $1.064^{*}$ & $1.058^{*}$ & $1.057^{*}$ & $1.054^{*}$ \\
\hline Hispanic vs White ${ }^{\#}$ & 1.020 & 1.303 & 1.289 & 1.587 & 1.984 & 1.718 & 1.908 & 1.237 \\
\hline Multi-Racial vs White & 0.763 & 1.162 & 1.495 & 1.131 & 0.559 & 1.904 & 1.000 & 0.860 \\
\hline Non-Hispanic Black vs White ${ }^{\#}$ & $2.117^{*}$ & $1.544^{\star}$ & $1.362^{*}$ & $1.735^{\star}$ & $1.453^{*}$ & 1.194 & 1.301 & 1.054 \\
\hline Other vs White & 2.173 & 0.535 & $2.993^{*}$ & 1.750 & 0.927 & 1.493 & 1.988 & 0.591 \\
\hline Region 1 vs 14 & 1.211 & 1.146 & $0.650^{*}$ & 0.805 & 0.904 & $0.598^{*}$ & $0.626^{*}$ & 0.835 \\
\hline Region 2 vs 14 & 1.030 & 0.683 & $0.476^{*}$ & 0.680 & $0.558^{*}$ & $0.606^{*}$ & $0.501^{*}$ & 0.783 \\
\hline Region 3 vs 14 & 1.068 & 1.150 & 0.696 & $0.553^{*}$ & 0.773 & 0.715 & $0.538^{*}$ & 0.760 \\
\hline Region 4 vs 14 & 0.846 & 1.022 & 0.754 & 0.722 & 0.774 & $0.433^{*}$ & $0.551^{*}$ & 0.824 \\
\hline Region 5 vs 14 & 1.009 & 1.080 & $0.511^{*}$ & 0.684 & 0.725 & $0.579 *$ & $0.512^{*}$ & 0.743 \\
\hline Region 6 vs 14 & 0.909 & 0.903 & 0.575 & $0.605^{*}$ & 0.740 & 0.642 & $0.623^{*}$ & 0.866 \\
\hline Region 7 vs 14 & 1.233 & 1.030 & 0.591 & 0.709 & 0.843 & $0.483^{*}$ & $0.634^{*}$ & 0.676 \\
\hline Region 8 vs 14 & 1.255 & 0.950 & 0.781 & 0.823 & 0.820 & $0.570^{*}$ & $0.564^{*}$ & 1.004 \\
\hline Region 9 vs 14 & 1.069 & 1.111 & $0.577^{*}$ & 0.873 & 0.956 & $0.596^{*}$ & $0.679^{*}$ & 0.778 \\
\hline Region 10 vs 14 & 1.305 & 1.211 & $0.607^{*}$ & 0.671 & 1.031 & 0.721 & $0.535^{\star}$ & 1.081 \\
\hline Region 11 vs 14 & 1.299 & 1.712 & 0.639 & 0.895 & 1.049 & $0.559 *$ & 0.843 & 1.070 \\
\hline Region 12 vs 14 & 0.952 & 1.085 & $0.553^{*}$ & 0.950 & 0.988 & $0.549 *$ & 0.850 & 0.609 * \\
\hline Region 13 vs 14 & 2.077 & 1.028 & 1.030 & 0.906 & 0.863 & 0.712 & 0.830 & 0.966 \\
\hline
\end{tabular}

"Denotes non-Hispanic White

*Denotes the odds ratio falls within the $95 \%$ confidence interval

Table 6. Odds Ratio Estimates and Significance for Incidence of Heart Disease per year

\begin{tabular}{|c|c|c|c|c|c|c|c|c|}
\hline Parameter & 2011 & 2012 & 2013 & 2014 & 2015 & 2016 & 2017 & 2018 \\
\hline Weight & $1.012^{*}$ & $1.008^{\star}$ & $1.007^{\star}$ & $1.007^{*}$ & $1.007^{\star}$ & $1.008^{*}$ & $1.007^{\star}$ & $1.007^{*}$ \\
\hline College 1 - 3 years vs < high school & 0.706 & 0.937 & 0.726 & 1.211 & 1.469 & $0.444^{*}$ & 1.010 & 0.836 \\
\hline College $>4$ years vs $<$ high school & $0.551^{*}$ & $0.594^{*}$ & 0.705 & 1.034 & 1.201 & $0.354^{*}$ & 0.978 & 0.595 \\
\hline Grade 12 or GED vs < high school & 0.686 & 0.871 & 0.917 & 1.002 & 1.259 & $0.423^{*}$ & 1.010 & 0.788 \\
\hline Income $\geq \$ 25 k<\$ 35 k$ vs $<\$ 25 k$ & 1.165 & 0.698 & 0.775 & $0.609^{*}$ & 0.840 & $0.645^{\star}$ & $0.670^{*}$ & 0.824 \\
\hline Income $\geq \$ 35 k<\$ 50 k$ vs $<\$ 25 k$ & 0.772 & 0.566 & $0.566^{*}$ & 0.809 & $0.567^{*}$ & 0.735 & $0.527^{*}$ & 0.793 \\
\hline Income $\geq \$ 50 k<\$ 75 k$ vs $<\$ 25 k$ & $0.598^{*}$ & 0.880 & $0.512^{*}$ & $0.568^{*}$ & $0.531^{*}$ & $0.618^{*}$ & $0.570^{*}$ & 0.865 \\
\hline Income $\geq \$ 75 k$ vs $<\$ 25 k$ & $0.477^{*}$ & $0.590^{*}$ & $0.494^{*}$ & $0.474^{*}$ & $0.460^{*}$ & $0.633^{*}$ & $0.510^{\star}$ & $0.658^{*}$ \\
\hline Age & $1.066^{*}$ & $1.063^{*}$ & $1.076^{\star}$ & $1.075^{\star}$ & $1.070^{*}$ & $1.066^{*}$ & $1.074^{*}$ & $1.076^{*}$ \\
\hline Hispanic vs White & $0.140^{*}$ & 1.196 & 0.553 & $0.352^{*}$ & 0.561 & 0.385 & 2.279 & 1.484 \\
\hline Multi-Racial vs White ${ }^{\#}$ & 0.765 & 1.917 & $4.384^{*}$ & 0.639 & $2.233^{*}$ & 0.482 & 1.549 & 0.823 \\
\hline Non-Hispanic Black vs White ${ }^{\#}$ & 0.649 & 0.823 & $0.445^{*}$ & 0.929 & 1.085 & 0.668 & 0.756 & 0.717 \\
\hline Hispanic vs White ${ }^{\#}$ & 0.394 & 0.591 & 1.104 & 0.673 & 0.847 & 1.126 & 2.602 & $4.020^{*}$ \\
\hline Region 1 vs 14 & 1.062 & 0.965 & 0.970 & 1.009 & 0.596 & 1.524 & 0.801 & 0.742 \\
\hline Region 2 vs 14 & 1.160 & 0.928 & 0.665 & 1.171 & $0.544^{*}$ & 1.837 & 0.633 & 0.829 \\
\hline Region 3 vs 14 & 1.072 & 0.983 & 0.808 & 0.786 & $0.407^{*}$ & 1.428 & 0.619 & 0.726 \\
\hline Region 4 vs 14 & 1.237 & $0.588^{*}$ & 0.890 & 0.566 & $0.329^{*}$ & 1.365 & $0.455^{*}$ & 0.787 \\
\hline Region 5 vs 14 & 1.298 & 1.014 & 0.821 & 0.690 & $0.320^{*}$ & 1.282 & $0.502^{*}$ & 0.853 \\
\hline Region 6 vs 14 & 1.835 & 0.887 & 0.630 & 0.610 & $0.469^{*}$ & 1.563 & $0.483^{*}$ & 0.825 \\
\hline Region 7 vs 14 & 1.057 & 0.572 & 0.804 & 0.778 & $0.334^{*}$ & 1.077 & 0.496 & 0.982 \\
\hline Region 8 vs 14 & 1.402 & 1.055 & 1.017 & 0.634 & $0.330^{*}$ & 0.746 & $0.347^{*}$ & $0.554^{*}$ \\
\hline Region 9 vs 14 & 0.988 & 0.755 & 0.851 & 0.857 & 0.751 & 1.153 & 0.691 & 0.792 \\
\hline Region 10 vs 14 & 1.018 & 0.825 & 0.871 & 0.871 & $0.491^{*}$ & 1.073 & 0.671 & 0.774 \\
\hline Region 11 vs 14 & 1.250 & 0.975 & 0.921 & 1.076 & 0.589 & 1.396 & 0.872 & 0.804 \\
\hline Region 12 vs 14 & 1.552 & 1.500 & 0.833 & 1.024 & 0.775 & 1.257 & 0.723 & 0.713 \\
\hline Region 13 vs 14 & 1.549 & 0.794 & 1.214 & 1.201 & 0.597 & 1.449 & 0.756 & 1.086 \\
\hline
\end{tabular}

"Denotes non-Hispanic White

*Denotes the odds ratio falls within the $95 \%$ confidence interval 
ficients were recorded in 5 of the 8 years and 6 of the 8 years for the $\$ 50000$ to $\$ 75000$ level. When income was over $\$ 75000$, all 8 years had negative coefficients. Evidence from other studies have verified this finding and point out the gap between the higher income groups and lower groups is getting wider. ${ }^{50,51}$

Table 7 displays, for both incidences of diabetes and heart disease, the decreasing average magnitudes of the odds ratio estimates per income level for the length of the study.

The decreasing averages suggest that at income levels above $\$ 25000$, the odds of a person developing diabetes compared to a person with income lower than $\$ 25000$ will decrease-in some cases more than $10 \%$. In comparing the average decline, income had a larger effect on incidence of diabetes than on the incidence of heart disease.

One of the purposes of this study was to examine if living within a certain region contributed to diabetes or heart disease. However, logistic regression estimates did not reveal sufficient evidence to verify this finding. The logistic regression did indicate that certain income levels have a strong influence on diabetes regardless of region. The same result occurred with the analysis of heart disease.

One interesting observation is that, in terms of regional effects, the year of study made a difference. For example, in the diabetes analysis, the odds ratios point estimates were significant in several regions for the years 2013, 2016, and 2017. For heart disease, the years 2015 and 2017 indicated evidence of regional effects. This could be because those regions had a significant change in income during the study time frame.

Furthermore, the study indicated that some regions, compared to Region 14, had higher odds of having both diabetes and heart disease. For example, Table 5 shows that for 2011, the odds ratio point estimates of having diabetes were greater than 1 in 10 of the 13 regions compared to Region 14 , which is the poorest in the state. With income having such a strong influence on both diseases, one would think the other regions compared to the poorest region would all have point estimates less than 1 . An odds ratio point estimate less than 1, is interpreted to mean, in this study, an individual living in that region is less likely to have diabetes. This surprising result may be indicative that diabetes may not be a regional phenomenon in Ohio. The same pattern was observed for heart disease. However, looking across the years of the study, the overall odds ratio estimates seem to decrease indicating changes in the incidences of the diseases. This is especially true for the later years of the study. In 2017, for diabetes, the odds ratios for all 13 regions were less than 1 , and 10 of the 13 regions were less than 1 in 2018. For heart disease, the results were similar for 2017 and in 2018. Only 1 region was greater than 1 . Regional effects may be more dependent on national economic events rather than regional characteristics. Or it could mean state efforts to control these diseases are effective across regions. More study needs to be undertaken to understand this trend.

Age and weight across the whole extent of the study were significant and positively related to having diabetes and heart disease. This result is not a surprise and reinforces the need for a healthy lifestyle.

Those individuals who had at least a high school education and above, generally had lower incidence of both diseases. In some years, there were slight increases in the odds ratio, but overall the more educated individuals had lower incidences of both diseases.

The study also indicated that non-Hispanic Blacks were more likely to have diabetes compared to non-Hispanic Whites (Table 5), but not as likely to have heart disease (Table 6). This is another rather surprising finding and needs to be evaluated separately. A study that looks at income, access to healthy food, and exercise patterns is needed to further analyze this aspect in more detail.

\section{PUBLIC HEALTH IMPLICATIONS}

The level of income is, perhaps, the most meaningful finding of this study and plays a significant role in the incidence of both diabetes and heart disease. The logistic regression estimates start to become negative in the $\$ 35000$ to $\$ 50000$ range of income indicating that an individual with income in this range will see better health outcomes than those with incomes below $\$ 35000$. Health care policy directed toward aiding those with low incomes could offer potential positive health care benefits regarding diabetes and heart disease.

\section{Income Enhancement Programs}

Since an increase in income is associated with decreasing incidence of both diabetes and CVD, any programs designed to embellish income would be helpful.48,52 Although there are a variety of income-related tools available to state lawmakers the Earned In-

\section{Table 7. Eight Year Average Odds Ratio (OR) per Income Level-Diabetes and Heart Disease}

\begin{tabular}{|lll|}
\hline Income Level & $\begin{array}{l}\text { Average Odds Ratio } \\
\text { Diabetes }\end{array}$ & $\begin{array}{l}\text { Average Odds Ratio } \\
\text { Heart Disease }\end{array}$ \\
$\begin{array}{l}\text { Greater than or equal to } \$ 25000 \text { but less than } \$ 35000 \text { vs Less than } \$ 25000 \\
\text { Greater than or equal to } \$ 35000 \text { but less than } \$ 50000 \text { vs Less than } \$ 25000\end{array}$ & 0.840 & 0.778 \\
Greater than or equal to $\$ 50000$ but less than $\$ 75000$ vs Less than $\$ 25000$ & 0.658 & 0.667 \\
Greater than or equal to $\$ 75000$ vs Less than $\$ 25000$ & 0.528 & 0.643 \\
\hline
\end{tabular}


come Tax Credit (EITC), a program already in place in Ohio, would be ideal. The EITC is currently included as a part of the federal tax code and has also been implemented by 28 states to reduce poverty. Twenty-two of those states utilize a refundable tax credit that pays the amount of the credit to taxpayers who are eligible for a refund. However, 6 states, including Ohio, only offer a nonrefundable tax credit. Nonrefundable tax credits offer relief up to the amount of taxes owed. For example, if an individual is eligible for a $\$ 1500$ tax credit, but owes $\$ 1000$ in taxes, that individual would only be given $\$ 1000-$ not the full amount of the credit. This does little to increase income and improve health outcomes for those living near or below the poverty line, and according to Policy Matters Ohio, an Ohio think tank, the EITC program in Ohio only affects about $5 \%$ of the neediest families. ${ }^{53}$

Other innovative programs are being attempted in other locales. Some of these programs include financial counseling, financial coaching, rules-of-thumb aids to income enhancement, financial education, individualized development accounts, children's savings accounts, incentivized tax-time savings accounts, prize-linked savings, credit building, reduced savings penalties, state intraagency collaboration to enhance overall state health, increased access to early childhood care and education programs, increases to the state minimum wage, low barriers to food assistance programs such as the Supplemental Nutrition Assistance Program (SNAP), and ease of access to public benefit programs such as rent, utility, and food assistance. ${ }^{53,54}$

Food Taxes and Subsidies

A recent meta-analysis has shown that "food pricing changes through taxation, subsidies, and other factors" can have positive effects on health. The study indicated that when prices were decreased on healthful foods the percentage change in consumption was greater than the percentage decrease in price. It was also found that when prices of unhealthful foods and beverages increased through taxation, the percentage change in consumption decreased, but by a lower percentage than the percentage change in price. ${ }^{55}$ This would suggest that the health of Ohioans might benefit by some type of food subsidy program.

Some cities, such as Boulder, Colorado; the District of Columbia; Philadelphia, Pennsylvania; Seattle, Washington; and 4 California cities (Albany, Berkeley, Oakland, and San Francisco), have enacted soda taxes. ${ }^{56}$ There is evidence that an additional tax on sugarladen soft drinks decreases consumption of these beverages. ${ }^{57}$ Less sugar usually means increasing levels of health. However, at this point in the US no statewide tax on the sugar in soda has been enacted.

Existing programs such as SNAP offer some assistance to those individuals and households in poverty. Although eligibility requirements are primarily set by the federal government, they can be modified by the individual states who administer the SNAP programs. In 2020, an individual eligible for SNAP benefits aver- aged about $\$ 125$ per month while households received an average of $\$ 246$ per month. Although this may seem like a reasonable amount of money, it works out to about $\$ 1.39$ per person per meal, hardly an amount for a feast. ${ }^{58}$ As such, Policy Matters Ohio suggests the state change its work requirements regarding SNAP benefits. Eligibility for SNAP benefits in Ohio is dependent on a set of work requirements. The mandate to "exempt all areas that meet exemption guidelines" applies until the federal requirements on work are eliminated. 53 Ohio currently exempts a few mostly rural areas from the work requirement while ignoring urban area exemptions. Policy Matters Ohio suggests making all areas exempt, which would increase the number of persons eligible for SNAP benefits. ${ }^{53}$

A few in-kind programs are available in Ohio such as The Emergency Food Assistance Program (TEFAP) and the Commodity Supplemental Food Program (CSFP), and these could be expanded. The less income spent on food leaves more to spend on health care.

As mentioned previously, diet plays a crucial role in prevention of both diabetes and CVD. It is known that increased consumption of fresh fruits and vegetables can reduce the risk for both diabetes and heart disease.59,60 Improving nutrition in poor communities may therefore help in preventing and controlling the incidence of both diabetes and CVD. Quality of nutrition is determined not only by affordability but also by availability of healthy food which is dependent on area of residence and ultimately on socioeconomic status. In this regard, opening subsidized grocery stores in lowincome areas that are readily accessible and affordable will prove beneficial.

\section{Regional Differences}

Regional differences were not significant in this study apart from years 2013, 2016, and 2017 for diabetes and 2015 and 2017 for heart disease. In these years, the estimated odds ratios were significant for several regions. This incompatibility could be attributed to some type of sampling bias or some negative event in the local economy such as a plant closing. With this finding in mind, policy efforts should probably target the entire state rather than specific regions. Although some pockets of regional and local poverty and health problems persist, local governments and other interested parties are better prepared to identify those areas and address remediation through existing channels.

\section{Collaboration}

To improve the state's response to diabetes and heart disease, a collaborative and unified effort among the various departments would be appropriate. For example, Ohio's Creating Healthy Communities (CHC) program receives funding from the Centers for Disease Control and Prevention's (CDC) Preventive Health and Health Services Block Grant Program. ${ }^{61}$ As of 2019, these funds support community health programs in 23 counties in Ohio.62 Collaboration starts at the local level with various concerned par- 
ties meeting, identifying problems, and then submitting a competitive application for a grant from the Ohio Department of Health. At the state level, each application is viewed and evaluated by a committee consisting of various health care officials and professionals representing different areas of expertise.

Another program that encourages collaboration among the various stakeholders is the State Health Improvement Plan (SHIP). The goal of the SHIP program is "to improve health, well-being and economic vitality in Ohio" by leveraging the resources of 13 state agencies. Advisory committees and input from subject matter experts from around the state are used to formulate the plan. ${ }^{63}$ At the local level, public and private partnerships focus on the 3 priority factors of improving community conditions, addressing health behaviors, and increasing access to care along with improving the 3 priority health outcomes of mental health and addiction, chronic disease, and maternal and infant health. 63

Leveraging the use of federal monies and increasing the collaboration among state agencies is an efficient way to deliver services without duplication of effort at both the state and local levels. The Ohio Department of Health should continue to pursue such activities as a cost-effective solution to chronic diseases such as diabetes and heart disease.

\section{ACKNOWLEDGMENTS}

The authors received no financial support for the research, authorship, or publication of this article.

The authors would like to thank Dean Spalsbury and Mr. Lance Williams and the IT Department of the Kent State University Geauga Campus for their support along with colleagues who provided helpful comments and insights: Professors Joseph Kratky, Mahli Mechenbier, Judith Paternite and Ms. Kristin Yeager of the Kent State Library's Research Support Service. Especially helpful in obtaining the necessary data was Ms. Justina Sleesman, the Ohio BRFSS Coordinator for the Ohio Department of Health. In addition, the authors are appreciative of the helpful comments and suggestions provided by the anonymous reviewers.

\section{REFERENCES}

1. American Diabetes Association. Diagnosis and classification of diabetes mellitus. Diabetes Care. 2009 Jan;32(Suppl 1):S62-67. https://doi.org/10.2337/dc09-S062

2. Centers for Disease Control and Prevention (CDC). Prevalence of overweight and obesity among adults with diagnosed diabetes--United States, 1988-1994 and 1999-2002. MMWR Morb Mortal Wkly Rep. 2004;53(45):1066-1068. https://pubmed.ncbi.nlm.nih.gov/15549021/

3. Deshpande AD, Harris-Hayes M, Schootman M. Epidemiology of diabetes and diabetes-related complications. Phys Ther. 2008;88(11):12541264. https://doi.org/10.2522/ptj.20080020

4. Ohio Department of Health. Ohio Diabetes Action Plan 2018. November 28, 2018.

https://odh.ohio.gov/wps/portal/gov/odh/know-our-programs/ chronic-disease/data-publications/Ohio-Diabetes-Action-Plan-2018

5. Jia H, Lubetkin EI. The impact of obesity on health-related quality-oflife in the general adult US population. J Public Health. 2005;27(2):
156-164.

https://doi.org/10.1093/pubmed/fdi025

6. Hamilton MT, Hamilton DG, Zderic TW. Sedentary behavior as a mediator of type 2 diabetes. Med Sport Sci. 2014;60:11-26. https://doi.org/10.1159/000357332

7. Maddatu J, Anderson-Baucum E, Evans-Molina C. Smoking and the risk of type 2 diabetes. Transl Res. 2017;184:101-107. https://doi.org/10.1016/j.trsl.2017.02.004

8. Sami W, Ansari T, Butt NS, Hamid MRA. Effect of diet on type 2 diabetes mellitus: A review. Int J Health Sci (Qassim). 2017;11(2):65-71.

9. Cheema A, Adeloye D, Sidhu S, Sridhar D, Chan KY. Urbanization and prevalence of type 2 diabetes in Southern Asia: A systematic analysis. $J$ Glob Health. 2014;4(1):010404.

https://doi.org/10.7189/jogh.04.010404

10. Galaviz KI, Narayan KMV, Lobelo F, Weber MB. Lifestyle and the prevention of type 2 diabetes: A status report. Am J Lifestyle Med. 2015;12 (1):4-20. Published 2015 Nov 24. https://doi.org/10.1177/1559827615619159

11. Asif M. The prevention and control the type-2 diabetes by changing lifestyle and dietary pattern. J Educ Health Promot. 2014;3:1. Published 2014 Feb 21. https://doi.org/10.4103/2277-9531.127541

12. Trowell HC and Burkitt DP, 1981. Western Diseases, Their Emergence and Prevention. Cambridge (Massachusetts): Harvard University Press, p. 456.

13. Benjamin EJ, Virani SS, Callaway CW, et al. Heart disease and stroke statistics-2018 update: A report from the American heart association. Circulation. 2018;137(12):e67-e492. https://doi.org/10.1161/CIR.0000000000000558

14. Ezzati M, Vander Hoorn S, Lawes CMM, et al. Rethinking the "diseases of affluence" paradigm: Global patterns of nutritional risks in relation to economic development. PLoS Med. 2005;2(5):e133. https://doi.org/10.1371/journal.pmed.0020133

15. Yu E, Malik VS, Hu FB. Cardiovascular disease prevention by diet modification: JACC health promotion series. J Am Coll Cardiol. 2018;72 (8):914-926. https://doi.org/10.1016/j.jacc.2018.02.085

16. Folta SC, Paul L, Nelson ME, et al. Changes in diet and physical activity resulting from the Strong Hearts, Healthy Communities randomized cardiovascular disease risk reduction multilevel intervention trial. Int J Behav Nutr Phys Act. 2019;16(1):91. https://doi.org/10.1186/s12966-019-0852-z

17. Darmon N, Drewnowski A. Does social class predict diet quality? Am J Clin Nutr. 2008;87(5):1107-1117. https://doi.org/10.1093/ajcn/87.5.1107

18. Darmon N, Drewnowski A. Contribution of food prices and diet cost to socioeconomic disparities in diet quality and health: A systematic review and analysis. Nutr Rev. 2015;73(10):643-660. https://doi.org/10.1093/nutrit/nuv027

19. Pechey R, Monsivais P. Socioeconomic inequalities in the healthiness of food choices: Exploring the contributions of food expenditures. Prev Med. 2016;88:203-209. https://doi.org/10.1016/j.ypmed.2016.04.012

20. Sacco RL, Elkind M, Boden-Albala B, et al. The protective effect of moderate alcohol consumption on ischemic stroke. JAMA. 1999;281(1):53- 
60.

https://doi.org/10.1001/jama.281.1.53

21. Elkind MSV, Sciacca R, Boden-Albala B, Rundek T, Paik MC, Sacco RL. Moderate alcohol consumption reduces risk of ischemic stroke: The northern Manhattan study. Stroke. 2006;37(1):13-19. https://doi.org/10.1161/01.STR.0000195048.86810.5b

22. Van Oers JA, Bongers IM., van de Goor LA, Garretsen HF. Alcohol consumption, alcohol-related problems, problem drinking, and socioeconomic status. Alcohol. 1999;34:78-88. https://doi.org/10.1093/alcalc/34.1.78

23. Bongers IM, van Oers HA, van de Goor IA, Garretsen HF. Alcohol use and problem drinking: Prevalences in the General Rotterdam population. Subst Use Misuse. 1997;32(11):1491-1512. https://doi.org/10.3109/10826089709055874

24. Erskine S, Maheswaran R, Pearson T, Gleeson D. Socioeconomic deprivation, urban-rural location and alcohol-related mortality in England and Wales. BMC Public Health. 2010;10:99. https://doi.org/10.1186/1471-2458-10-99

25. Snopek L, Mlcek J, Sochorova L, et al. Contribution of red wine consumption to human health protection. Molecules. 2018;23(7):1684. https://doi.org/10.3390/molecules23071684

26. Galea S, Tracy M, Hoggatt KJ, Dimaggio C, Karpati A. Estimated deaths attributable to social factors in the United States. Am J Public Health. 2011;101(8):1456-1465 https://doi.org/10.2105/AJPH.2010.300086

27. Mackenbach JP, Cavelaars AE, Kunst AE, Groenhof F. Socioeconomic inequalities in cardiovascular disease mortality. An international study. Eur Heart J. 2000;21(14):1141-1151. https://doi.org/10.1053/euhj.1999.1990

28. Davari M, Maracy MR, Khorasani E. Socioeconomic status, cardiac risk factors, and cardiovascular disease: A novel approach to determination of this association. ARYA Atheroscler. 2019;15(6):260-266. https://doi.org/10.22122/arya.v15i6.1595

29. Kreatsoulas C, Anand SS. The impact of social determinants on cardiovascular disease. Can J Cardiol. 2010;26(Suppl C):8C-13C. https://doi.org/10.1016/S0828-282X(10)71075-8

30. Schwartz F, Ruhil AVS, Denham S, Shubrook J, Simpson C, Boyd SL. High self-reported prevalence of diabetes mellitus, heart disease, and stroke in 11 counties of rural Appalachian Ohio. J Rural Health. 2009;25(2):226-230. https://doi.org/10.1111/j.1748-0361.2009.00222.x

31. Ebron, DL and SJ Paton. Health Profiles-Diabetes-Montgomery County Ohio, Epidemiology Section. 2014. Accessed July 5, 2021. https://www.phdmc.org/epidemiology/health-profiles/110-healthprofile-diabetes/file

32. Sleesman, J. and H. Sobotka. Ohio 2018 Behavioral Risk Factor Surveillance Survey (BRFSS) Annual Report. Ohio Department of Health. Chronic Disease Epidemiology and Evaluation Section, Bureau of Health Improvement and Wellness. Accessed July 6, 2021. https://odh.ohio.gov/wps/wcm/connect/gov/e3a68ed6-687d-4afd-9bedc24f5310280e/Ohio+BRFSS+2018+Annual+Report.pdf? MOD $=$ AJPERES\&CONVERT_TO $=$ url\&CACHEID $=$ ROOTWORKSPACE.Z18_M1HGG K0N0J000Q09DDDDM3000-e3a68ed6-687d-4afd-9bed-c24f5310280e-n9he2PT

33. The Behavioral Risk Factor Surveillance System (BRFSS). Survey Data and Documentation. Center for Disease Control and Prevention. Ac- cessed September 23, 2020.

https://www.cdc.gov/brfss/data_documentation/index.htm

34. Ohio Department of Health. Behavioral Risk Factor Surveillance System: Accessed July 14, 2020. https://odh.ohio.gov/wps/portal/gov/odh/know-our-programs/ behavioral-risk-factor-surveillance-system/welcome-to

35. The Behavioral Risk Factor Surveillance System (BRFSS), OVERVIEW: BRFSS 2018, July 26, 2019, p. 4. Accessed July 16, 2020.

The Behavioral Risk Factor Surveillance System (BRFSS) Overview 2018 (cdc.gov)

36. Clark ML, Utz SW. Social determinants of type 2 diabetes and health in the United States. World J Diabetes. 2014;5(3):296-304.

https://doi.org/10.4239/wjd.v5.i3.296

37. Ohio 2108 Codebook Report, Overall Version Weighted with_LLCPWT Behavioral Risk Factor Surveillance System, July 26, 2019, p. 29. SAS Variable names: DIABETE3, CVDCRHD4, WEIGHT2, INCOME2, EDUCA, _RACE3.

The Behavioral Risk Factor Surveillance System (BRFSS) Overview 2018 (cdc.gov)

38. US Census Bureau. 2019. Small Area Income and Poverty Estimates Program (SAIPE). Yearly median income per county 2011-2018. https://www.census.gov/data-tools/demo/saipe/\#/? map_geoSelector $=$ mhi_c\&s_state $=39 \&$ s_year $=2019,2018,2017 \&$ s_me asures $=$ mhi_snc

39. Appalachian Regional Commission. County Economic Status and Number of Distressed Areas in Appalachian Ohio, Fiscal Year 2020. Accessed September 23, 2020. https://www.arc.gov/wp-content/uploads/2020/08/ CountyEconomicStatusandDistressAreasFY20200hio.pdf

40. Diabetes Report Card 2019. National and State Diabetes Trends. Centers for Disease Control and Prevention, Accessed July 4, 2021. https://www.cdc.gov/diabetes/library/reports/reportcard/nationalstate-diabetes-trends.html

41. Graham G. Disparities in cardiovascular disease risk in the United States. Curr Cardiol Rev. 2015;11(3):238-245. https://doi.org/10.2174/1573403X11666141122220003

42. Schreiber-Gregory D, Jackson HM. Logistic and linear regression assumptions: Violation recognition and control. Paper 247-2018. Accessed January 28, 2021.

https://www.researchgate.net/publication/341354759_Logistic_and_ Linear_Regression_Assumptions_Violation_Recognition_and_Control

43. Tabachnick, BG and Fidell, LS. Using Multivariate Statistics. 5th ed. Pearson. 2007.

44. Hsieh FY. Sample size tables for logistic regression. Stat Med. 1989;8 (7):795-802. https://doi.org/10.1002/sim.4780080704

45. Introduction to SAS. UCLA: Statistical Consulting Group. Introduction to the features of SAS. Accessed January 27, 2021.

https://stats.idre.ucla.edu/sas/modules/introduction-to-the-featuresof-sas /

46. Introduction to SAS. UCLA: Statistical Consulting Group. Logit Regression | SAS Data Analysis Examples (ucla.edu). Accessed February 7, 2012.

https://stats.idre.ucla.edu/sas/dae/logit-regression/

47. SAS Institute Inc. 2019, SAS/STAT User's Guide, Version 15.1, Cary, NC: SAS Institute Inc. The LOGISTICS Procedure, Odds Ratio Estimation. 
Copyright (C) SAS Institute Inc. All rights reserved. https://documentation.sas.com/doc/en/pgmsascdc/9.4_3.4/statug/ statug_logistic_details28.htm

48. Bird Y, Lemstra M, Rogers M, Moraros J. The relationship between socioeconomic status/income and prevalence of diabetes and associated conditions: A cross-sectional population-based study in Saskatchewan, Canada. Int J Equity Health. 2015;14:93. https://doi.org/10.1186/s12939-015-0237-0

49. Beckles GL, Chou CF. Disparities in the Prevalence of Diagnosed Diabetes - United States, 1999-2002 and 2011-2014. MMWR Morb Mortal Wkly Rep. 2016;65(45):1265-1269. Published 2016 Nov 18. https://doi.org/10.15585/mmwr.mm6545a4

50. Abdalla SM, Yu S, Galea S. Trends in cardiovascular disease prevalence by income level in the United States. JAMA Netw Open. 2020;3(9): e2018150. https://doi.org/10.1001/jamanetworkopen.2020.18150

51. Schultz et al. Socioeconomic status and cardiovascular outcomes. Circulation. 2018;137:2166-2178. https://doi.org/10.1161/CIRCULATIONAHA.117.029652

52. Dinca-Panaitescu S, Dinca-Panaitescu M, Bryant T, Daiski I, Pilkington B, Raphael D. Diabetes prevalence and income: Results of the Canadian Community Health Survey. Health Policy. 2011;99(2):116-123. https://doi.org/10.1016/j.healthpol.2010.07.018

53. Woodrum, Amanda and Deanna Krokos. Building a Healthy Ohio. Policy Matters Ohio. November 19, 2018. https://www.policymattersohio.org/files/news/ buildingahealthyohiofinal11-19-2018.pdf

54. Butrica, B and Martinchek K with Galvez M, Hahn H, Signe-McKernan $\mathrm{M}$, and Spaulding S. Effective Programs and Policies for Promoting Economic Well-Being. Urban Institute Research Report, Feb. 2020. https://www.urban.org/research/publication/effective-programs-and -policies-promoting-economic-well-being

55. Afshin A, Peñalvo JL, Del Gobbo L, Silva J, Michaelson M, O’Flaherty M, et al. (2017) The prospective impact of food pricing on improving dietary consumption: A systematic review and meta-analysis. PLoS ONE 12(3):e0172277. https://doi.org/10.1371/journal.pone.0172277

56. Soda taxes. The Urban Institute's State and Local Finance Initiative. 2011. Accessed November 28, 2020.

https://www.urban.org/policy-centers/cross-center-initiatives/stateand-local-finance-initiative/state-and-local-backgrounders/sodataxes\#: :text=No\%20state\%20currently\%20has\%20an,\%2C\% 200akland\%2C\%20and\%20San\%20Francisco

57. Jacobson MF, Krieger J, Brownell KD. Potential policy approaches to address diet-related diseases. JAMA. 2018;320(4):341-342. https://doi.org/10.1001/jama.2018.7434

58. A Guide to SNAP Eligibility and Benefits. Updated September 1, 2020. Center on Budget and Policy Priorities. Accessed: November 28, 2020. https://www.cbpp.org/research/food-assistance/a-quick-guide-tosnap-eligibility-and-benefits

59. Wang PY, Fang JC, Gao ZH, Zhang C, Xie SY. Higher intake of fruits, vegetables or their fiber reduces the risk of type 2 diabetes: A metaanalysis. J Diabetes Investig. 2016;7(1):56-69. https://doi.org/10.1111/jdi.12376

60. Pallazola VA, Davis DM, Whelton SP, et al. A clinician's guide to healthy eating for cardiovascular disease prevention. Mayo Clin Proc Innov
Qual Outcomes. 2019;3(3):251-267.

https://doi.org/10.1016/j.mayocpiqo.2019.05.001

61. Creating Healthy Communities. 2010-2014 Program Evaluation Report. Ohio Department of Health. Accessed December 15, 2020. https://odh.ohio.gov/wps/wcm/connect/gov/206869c5-6754-42598b25-ce7f8c47dd2e/CHC+Program+Evaluation+Report.pdf? MOD=AJPERES\&CONVERT_TO $=$ url\&CACHEID $=$ ROOTWORKSPACE.Z1 8_M1HGGIK0N0J000Q09DDDDM3000-206869c5-6754-4259-8b25ce7f8c47dd2e-moRzbeQ

62. 2019 Success Stories. Ohio Department of Health. Accessed December $15,2020$. https://odh.ohio.gov/wps/portal/gov/odh/know-our-programs/ creating-healthy-communities/resources/2019-success-stories

63. SHIP--State Health Improvement Plan Ohio 2020-2022.Accessed December 17, 2020.

https://www.healthpolicyohio.org/2020-2022-state-healthimprovement-plan/ 